\title{
Forestería comunitaria en México: modelo estratégico para empoderamiento y competitividad en la globalización
}

\section{Community forestry in Mexico: strategic model for the empowerment and competitiveness in globalization}

\author{
ConCEPCión LujÁN-ÁLVAREZ* \\ Jesús Miguel Olivas-García* \\ Hilda Guadalupe González-Hernández** \\ Susana VÁZqueZ-ÁlLVAREZ $Z^{* * *}$ \\ José Ciro Hernández-Díaz **** \\ Humberto Luján-Álvarez ${ }^{* * * * *}$
}

\begin{abstract}
Resumen
Esta investigación diseña y propone un modelo estratégico integral para el empoderamiento y la competitividad de ejidos y comunidades forestales, considera los estados de Chihuahua, Durango, Jalisco y Michoacán como un sistema forestal. El modelo incluye la estrategia de integración horizontal y vertical de clústeres, el empoderamiento y participación comunitaria en mercados nacionales e internacionales, y tiene como objetivo fomentar la competitividad del desarrollo forestal comunitario en la globalización.
\end{abstract}

Palabras clave: competitividad forestal de ejidos, modelo holístico forestal, desarrollo forestal sustentable.

\section{Abstract}

This research was to design and propose a holistic strategic model for empowerment and competitiveness of forest ejidos and communities, considering the States of Chihuahua, Durango, Jalisco and Michoacan as a forest system. The model includes the strategy of horizontal and vertical integration of the forest clusters, empowerment, and involvement of the clusters in national and international markets. The model aims to foster the competitiveness of community forestry development in globalization.

Keywords: forest ejido competitiveness, holistic forestry model, sustainable forestry development.

\footnotetext{
*Universidad Autónoma de Chihuahua. Correos-e: clujan12@hotmail.com y jolivas@live.com.mx

** Programa de las Naciones Unidas-Conafor. Correo-e: hilda.gonzalez@conafor.gob.mx

*** Consultora Forestal. Correo-e: p76977@gmail.com

**** Universidad Juárez del Estado de Durango. Correo-e: jciroh@ujed.mx

***** Secretaría de Educación Pública. Correo-e: hlujan@prodigy.net.mx
} 


\section{Introducción}

\section{El paradigma de la competitividad sistémica, la globalización y la sustentabilidad}

La globalización económica ha ubicado a las naciones del mundo, sobre todo a las economías emergentes, ante un nuevo reto para sus estructuras políticas, sociales, culturales, económicas, ambientales, productivas, competitivas y de mercado, en las que se ha sustentado el desarrollo económico y de bienestar social, así como la dimensión ecológico-ambiental; todo esto con visión de desarrollo sustentable, lo cual significa que se enfrenta a la nueva era del conocimiento, la mentefactura, es decir, tomar como base la información y el conocimiento para la innovación y el desarrollo tecnológico.

Bajo este contexto, las empresas deben considerar para su desarrollo la estrategia "competitividad sistémica", es decir, que en su desempeño competitivo apliquen la interacción entre varios sistemas: a) sistema de la apertura económica y exposición a la globalización, b) sistema macroeconómico, c) sistema sectorial-industrial (densidad y solidez del tejido productivo de un país, estado, región y local), d) sistema institucionalEstado (reglas regulatorias para el mercado y la economía), e) sistema político-social, f) sistema microempresarial (núcleo base de la competitividad), y g) sistema ecológico ambiental; todo esto en el marco de la sustentabilidad (Villarreal y Ramos, 2002).

\section{Competitividad forestal, clústeres y apertura de mercados}

La competitividad forestal, la globalización y la competencia internacional impactan en la forma de operar de las empresas forestales; sin embargo, gracias a la apertura de mercados existen nuevas oportunidades y retos para permitir que las inversiones, el capital y las tecnologías aporten ventajas comparativas y competitivas para la operación de la empresa: 1) ventajas comparativas: costos de disponibilidad (materias primas, reducción de costos y cercanía), y 2) ventajas competitivas: desarrollo de habilidades y capacidades (tecnología, investigación e innovación).

Por lo tanto, los clústeres de Empresas Forestales Comunitarias (EFC) continúan emergiendo en diferentes lugares en el mundo (Cortave, 2003; Gill, 2002; Nolan, 2001; Scherr et al., 2003). Al mismo tiempo, los enfoques alternativos de desarrollo incluyen el "empoderamiento" e insisten en la importancia de las comunidades organizadas y de la acción de base (Friedmann, 1992; Hirschman, 1993; Redclift, 1987). En particular, relacionado con la industria forestal, los países Brasil, China y Rusia 
probablemente serán los jugadores más importantes en los mercados internacionales para el 2020 (FAO, 2007 citado por Smith y Cossio (2008).

En este contexto de competitividad y mercados, es importante referir el modelo de competitividad de Porter (1990), que ha sustentado el diseño y aplicación de estrategias de desarrollo de empresas, como un modelo óptimo para adaptar los factores de la competitividad del desarrollo sustentable de los ejidos y comunidades forestales y empresas forestales comunitarias en México.

\section{Contexto internacional: desarrollo forestal comunitario (DFC) y empresas forestales comunitarias (EFC)}

En relación con el desarrollo forestal comunitario internacional, la mayoría de los bosques en los países en vías de desarrollo aún son nacionales, pero los gobiernos han reconocido la propiedad de las comunidades sobre $14 \%$ de los bosques. México es el segundo país, después de Papúa, Nueva Guinea, en proporción de bosques en manos de comunidades (80\%) (Klooster, 2003).

En la mayoría de los países asiáticos, los bosques son manejados por poderosas burocracias forestales centralizadas que se benefician directamente de las ganancias provenientes de la madera. En Indonesia, la cuarta nación más poblada del mundo, el gobierno administra 99\% de los bosques, con solo $1 \%$ reservado para grupos indígenas y comunidades (Colchester, 2003). En la India, el Estado administra directamente 77\% de los bosques de la nación, 16\% están reservados a las comunidades y sólo 7\% a la propiedad privada. En contraste, en Estados Unidos, 56\% de los bosques son privados, $38 \%$ son tierras del gobierno, y $6 \%$ están reservados para los grupos indígenas.

No sorprende, entonces, que a nivel mundial (Pagdee et al., 2006) se destaquen entre algunos factores de éxito del desarrollo forestal comunitario los derechos de propiedad, coordinación y colaboración institucional, e intereses de las comunidades; en ninguna parte se menciona la importancia de la organización empresarial de las comunidades forestales. Por lo tanto, es necesario considerar el enfoque holístico en el manejo forestal comunitario sustentable, donde progresivamente se desarrollan de manera más consistente las dimensiones sociocultural, económica y ambiental vinculadas con la gestión forestal sustentable.

Referente a América Latina, una estrategia considerada en el desarrollo forestal comunitario (DFC) y en las empresas forestales comunitarias (EFC) ha sido el acompańamiento de organizaciones externas a la comunidad. Intenta remplazar la cultura tradicional de las comunidades por una cultura empresarial capaz de enfrentar y aprovechar los desafíos y oportunidades del mundo globalizado (Sabogal et al., 2008). 
Esta estrategia no ha sido muy exitosa a pesar de las grandes cantidades de recursos invertidos en periodos cortos. De ahí la necesidad de romper paradigmas para crear o fortalecer un marco de condiciones más favorables y más compatibles con la realidad del actor local; sin embargo, en el ámbito latinoamericano, México y algunos países de América Central son los más avanzados en la promoción del DFC y EFC. Adicionalmente, en América Latina prevalecen figuras jurídicas para el desarrollo forestal comunitario basadas en el otorgamiento de derechos usufructuarios: Petén, Guatemala, Honduras y Nicaragua, Brasil y Bolivia. En contraste, los derechos de propiedad comunal sólo se dan en pocos casos, como en los ejidos en México y Guatemala (Stoian y Donovan, 2008).

En particular, la conformación y el desarrollo de empresas forestales comunitarias surgió en la década del 2000, cuando se reconoció que el modelo de desarrollo forestal comunitario, no sólo debe ser sustentable en términos ecológicos y sociales, sino también económicamente viable. Por lo que el fortalecimiento de las capacidades empresariales de las comunidades, a través de la integración vertical de varios eslabones de la cadena productiva, se incluyó como parte de las estrategias para la reducción de la pobreza, principalmente en proyectos apoyados por la cooperación internacional (Sabogal et al., 2008). Estas consideraciones sustentan aún más la necesidad de diseñar e impulsar nuevos modelos estratégicos para el desarrollo forestal comunitario competitivo como el que se propone en esta investigación.

\section{Antecedentes del desarrollo forestal comunitario y empresas forestales comunitarias en México}

\subsection{Recursos forestales, régimen de propiedad y contextos socio- culturales y económicos}

En México, del total del territorio nacional, $72 \%$ es de aptitud forestal, con 56 millones 800 mil hectáreas arboladas, de las cuales alrededor de 21 millones 600 hectáreas tienen potencial para la producción maderable comercial. El sector forestal es reconocido a nivel internacional por la mega diversidad de especies que albergan sus ecosistemas y por la gran proporción de propiedad social de sus bosques, ya que $80 \%$ pertenece a Ejidos y Comunidades Forestales (EyCF) que son una forma de tenencia comunal de la tierra (Bray y Merino-Pérez, 2004).

Por otra parte, las áreas forestales del país están habitadas por $11 \mathrm{mi}-$ llones de personas; $37 \%$ de ellas carecen de acceso a servicios de salud y $15 \%$ tienen entre 15 años o más que no completaron la educación básica. Existen 43 etnias (integradas por cinco millones de indígenas) que viven 
en zonas forestales. A pesar de que sólo en 5\% de los ejidos y comunidades forestales el aprovechamiento forestal representa la actividad económica central, los bosques representan en todas ellas un recurso fundamental, ya que son fuente de alimentos, medicina, leña, materiales de construcción, entre otros, así como servicios que se comercializan y generan ingresos.

\subsection{Producción, productividad y consumo de productos forestales}

México tiene 2400 ejidos que aprovechan sus bosques, con productividad baja en bosque natural ( $1 \mathrm{~m}^{3} /$ ha/año). Sólo existen 51 empresas con certificación FSC, 34 en manejo forestal y 17 en cadena de custodia. De los bosques certificados $82 \%$ corresponde a empresas forestales comunitarias, mientras que $18 \%$ a empresas privadas. En contraste, la cadena de custodia, $71 \%$ son empresas privadas y $29 \%$ representan a empresas forestales comunitarias (Semarnat, 2011). Por otro lado, en el país, los principales estados productores forestales son Durango, Chihuahua, Michoacán, Oaxaca, Jalisco, Michoacán y Estado de México. Los principales productos forestales en México son la madera aserrada, celulósicos, tableros, postes y pilotes, leña y carbón y durmientes; de tal manera que el Producto Interno Bruto Forestal en promedio representa 1.2\% del PIB nacional (Semarnat-Conafor, 2004 y Semarnat, 2011).

Para el 2011, el consumo aparente de escuadría a nivel nacional fue de más de 20 millones de metros cúbicos, de los cuales sólo se produce alrededor de $19 \%$ en México, siendo este el concepto que representa el mayor volumen importado (Semarnat, 2011). Uno de los principales problemas que enfrenta la producción nacional de madera aserrada es la pérdida de competitividad frente a la madera de importación (Flores et al., 2007). En general, el consumo de productos forestales maderables en México es de $19,882,743 \mathrm{~m}^{3}$, y se produce $28 \%$ del consumo interno total maderable, por lo que $72 \%$ del consumo se abastece con productos importados, teniendo nuestro país una balanza comercial forestal negativa, en la cual los productos de papel significan el mayor porcentaje (65\%) del déficit de la balanza comercial forestal.

México no tiene una industria forestal desarrollada e integrada con todos los eslabones de una cadena productiva forestal debido a la falta de inversión económica, investigación científica y tecnológica. Por lo tanto, para desarrollar una industria forestal es necesario fomentar e impulsar la integración, tanto horizontal como vertical, de clústeres o agrupaciones de empresas (Linda et al., 1991); aumentar la participación en un mercado específico e incrementar el índice de ventaja comparativa (Porter, 1990). 


\subsection{Desarrollo de empresas forestales comunitarias y competitividad}

Relacionado con el sector de Empresas Forestales Comunitarias (EFC), México es uno de los países que mayores avances de desarrollo tiene en este rubro en América Latina (Bray et al., 2003). En relación con su nivel de integración, $52 \%$ de las empresas forestales comunitarias venden su producto en pie, $35 \%$, en troza, y $13 \%$ venden madera aserrada destinada al mercado local, regional y nacional. La mayoría de ellas está ubicada en los bosques templados de los estados de Chihuahua, Durango, Oaxaca, Michoacán, Jalisco, Guerrero y Puebla.

Como resultado de las reformas al artículo 27 constitucional y a la nueva Ley Forestal en 1992, el desarrollo forestal comunitario mexicano ha comenzado un esfuerzo explícito por extender y mejorar la silvicultura comunitaria, a través de la provisión de capacitación en el manejo de empresas y del bosque, incluyendo técnicas innovadoras de extensión de comunidad a comunidad, como se establece en el Programa Nacional Forestal 2013-2018 (Conafor, 2013; Klooster, 2003).

Por consiguiente, la forestería comunitaria es el eslabón base de la cadena productiva forestal, en la cual se ubican las EFC. Es una realidad que el desarrollo y nivel de competitividad de éstas han sido impactados por el proceso de la globalización económica, la estructura organizacional, la escasa cultura empresarial, la limitada reconversión industrial y particularmente por los paradigmas tradicionales que han caracterizado a la actividad forestal nacional y, que hasta ahora, han limitado su productividad, su competitividad y su empoderamiento (fortalecimiento de capacidades para la autogestión). De la misma manera, la escasa integración del clúster forestal (Bonita et al., 2002), caracterizada por la actuación desarticulada de los eslabones de la cadena forestal y, sobre todo, por la falta de fortalecimiento de procesos de asociatividad en diferentes niveles considerando los procesos de integración horizontal y vertical.

Por otra parte, el desarrollo forestal comunitario en México, y en particular las EFC han logrado contribuir, aunque de manera limitada, a reducir la pobreza por medio de la creación de empleo y de la distribución de las ganancias obtenidas con inversiones con el propio manejo; de tal manera que se espera fortalecer en el tiempo la integración vertical y horizontal y contribuir a mantener la biodiversidad y preservar el ambiente (Bray et al. 2003; Antinori y Bray, 2005). Sin embargo, la mayoría de los ejidos y EFC de México venden madera a compradores locales. Pocas EFC han logrado posicionarse en mercados regionales o internacionales para madera dimensionada y productos terminados, por ejemplo: El 
Balcón, Guerrero, San Juan Nuevo Parangaricutiro, Michoacán y Pueblos Mancomunados, Oaxaca.

En consecuencia, el modelo mexicano de desarrollo forestal comunitario y las EFC representan una respuesta a la pregunta: ¿quién puede salvar los bosques y cuáles son los acuerdos sociales necesarios para lograrlo?, se responde afirmativamente, ya que cuando la gente local tiene el control sobre el manejo forestal y los beneficios del bosque, frecuentemente logra grandes mejoras en el desarrollo rural.

Adicionalmente, en relación con modelos de competitividad para el manejo sustentable de bosques, agua y biodiversidad delineados en México, Galicia et al. (2009) establecen que se deben generar productos nuevos con mayor valor agregado, ya que estos son más dinámicos en los mercados mundiales. A su vez, Labandeira et al. (2007) y Alviar et al. (2007) indican que esto se logra por medio de procesos limpios, capacitación de recursos humanos, promoción de la articulación de los sectores productivo, gubernamental, académico y de investigación tecnológica que fomenten altas tasas de crecimiento. Por tal razón, Galicia et al. (2009) proponen un modelo de competitividad de los recursos agua, biodiversidad y forestales, considerando estrategia y estructura empresarial, condiciones de los factores, condiciones de la demanda e industrias de apoyo relacionadas, tomando como base el modelo de competitividad de Porter (1990).

En la propuesta del modelo de competitividad que plantea Galicia et al. (2009), se indican tres aspectos para impulsar la competitividad y el manejo sustentable de agua, biodiversidad y recursos forestales: 1) Incentivar la competitividad económica en las empresas, región, industria y país para fomentar el desarrollo de empresas forestales comunitarias (EFC) en ámbitos de productividad, legislación, entorno administrativo, ambiente productivo, integración en cadenas de valor, comercialización, creación de mercados internos, generación de empleos y bienestar para la comunidad; 2) La política pública para privilegiar los programas de fortalecimiento de capacidades productivas, simplificar y reducir la regulación del manejo forestal, y descentralizar la toma de decisiones en materia de economía forestal, a través del ejercicio de una política forestal consistente, y 3) El desarrollo de políticas y programas científicos de competitividad del manejo forestal sustentable deben estar concertadas y dirigidas a fomentar la innovación (valor agregado y nuevos productos), la ciencia y la tecnología, el desarrollo de infraestructura, el desarrollo de recursos humanos (la capacitación el desarrollo empresarial y la gobernanza), el financiamiento de actividades productivas y el manejo sustentable de energía y recursos naturales en los procesos productivos. 


\section{Desafíos del desarrollo forestal comunitario y empresas forestales comunitarias en México}

El desarrollo forestal comunitario, y en específico las EFC presentan importantes retos para el mejoramiento de sus niveles de producción, productividad, mercadeo de productos, y en sí, sus niveles de competitividad, en un contexto de globalización económica. Según Bray y Merino-Pérez (2004); Antinori y Bray (2005), algunos de estos retos:

a) Naturaleza de las EFC y su competitividad. Las EFC en México tienen algunas metas que no comparten con la mayoría de empresas de otra índole (ejem: privadas), como es la generación de empleo local (sin control estricto de costos), la acumulación de bienes sociales, las formas sociales de organización y la promoción de equidad (participación de los comuneros en la toma de decisiones y responsabilidades). Esto influye en que las EFC están limitadas en su nivel de competitividad nacional e internacional.

b) Rotación de los puestos de administración. En muchos casos, los puestos de administración cambian por votación de la asamblea general cada tres años, por lo que los ocupantes de los cargos rara vez llegan a desarrollar mucha experiencia y continuidad en los procesos de desarrollo. Ello genera ineficiencia en la administración de las empresas y crea necesidades de capacitación permanente del nuevo personal.

c) Limitaciones en el fortalecimiento de capacidades para el capital social y humano del ejido/comunidad o empresa forestal comunitaria. Los integrantes de la asamblea general, a menudo no tienen el conocimiento técnico, empresarial o financiero necesario para atender la administración de una empresa con criterios de eficiencia, eficacia y efectividad.

d) Las asambleas generales y el papel de la EFC. La mayoría de las asambleas generales consideran a la EFC como una fuente de empleo, inversión social y ganancias a repartirse, más que como empresas que deben manejarse para generar rentas. Por ello, las EFC suelen padecer problemas de capitalización.

e) Limitada participación de mujeres y jóvenes. Por tradición, las asambleas generales están dominadas por los hombres de mayor edad, mientras que las mujeres y los jóvenes tienden a no ocupar puestos claves en el sistema de gobernanza de las comunidades y, si los ocupan, son cargos con poco poder y responsabilidad. Por lo que es necesario fortalecer la estrategia de equidad de género en el desarrollo forestal comunitario 
f) Débil administración. En muchos casos, los ejidos y comunidades forestales y las EFC no cuentan con el desarrollo organizacionaladministrativo suficiente para establecer condiciones estrictas de transparencia, rendición de cuentas y sanción de infracciones relacionadas con el uso de los recursos comunes.

En consecuencia, como estrategia alternativa para avanzar favorablemente en dichos retos en el futuro y aprovechar oportunidades en el contexto externo se precisa la necesidad de establecer una visión sistémica a largo plazo y diferentes formas de acción concertada entre los actores claves, entre ellos ejidos y comunidades forestales, EFC, socios empresariales (procesadores y compradores) y proveedores de servicios, incluyendo agencias estatales y las ONG. Con ello, los procesos de integración horizontal y vertical y las alianzas o clústeres entre EFC y empresas privadas en otros eslabones de la cadena pueden conducir a inversiones conjuntas en tecnologías para fortalecer la infraestructura y la productividad, así como a la formación de capacidades para innovaciones en el diseño de productos y de la gestión empresarial (Vidal y Donini, 2004; Morsello, 2006). Todo esto con el propósito de impulsar la productividad, el empoderamiento y la competitividad de las EFC tanto en el ámbito local, regional, nacional e internacional, como se establece en el modelo propuesto, motivo de la presente investigación.

En suma, para lograr el desarrollo de la forestería comunitaria y de las EFC en México, se requiere aplicar modelos integrales con visión holística que promuevan la capacidad de respuesta y la suma de esfuerzos para obtener efectos sinérgicos que contribuyan a hacer frente a los retos antes mencionados. Por lo anterior, y ante las necesidades de nuevas alternativas de producción y mercadeo en el entorno forestal nacional y en la forestaría comunitaria en particular, se han realizado esfuerzos institucionales y por parte de los silvicultores, orientados a lograr mayor participación en los mercados, así como a integrar a los propios silvicultores en diferentes niveles. Aunque con resultados favorables, dichos esfuerzos han sido escasos y aislados, lo cual se ha reflejado en el estancamiento de la productividad forestal nacional y en su competitividad, y que sigue impactando desfavorablemente la balanza comercial forestal evidenciada en la Evaluación del Programa Estratégico Forestal 2025 (Semarnat-Conafor, 2001; Semarnat-Conafor, 2013a).

Por lo tanto, considerando la necesidad de un proceso de cambio orientado a desarrollar a largo plazo la forestería comunitaria competitiva y sustentable, y en particular la empresa forestal comunitaria, se realizó la presente investigación en ejidos y comunidades forestales de los estados de Chihuahua, Durango, Jalisco y Michoacán, los cuales aportan cerca 
de 70\% de la producción maderable nacional (Semarnat, 2011). El objetivo fue generar y proponer un modelo integral de desarrollo con visión holística para impulsar la competitividad y el empoderamiento de los ejidos y de las comunidades forestales, así como los mercados en el contexto de la globalización económica.

\section{Metodología}

\section{1. Área de estudio}

La investigación se realizó en México en el 2009, en los estados de Chihuahua, Durango, Jalisco y Michoacán, considerados en conjunto como un sistema forestal por sus condiciones similares de ejidos y comunidades forestales con bosques de clima templado frío, y por ser los de mayor producción forestal en México (mapa I).

\subsection{Sujetos de estudio}

De acuerdo con el nivel de integración de los silvicultores y las categorías establecidas de tipología de productores forestales por la Semarnat-Conafor (2013b), se consideró la siguiente tipología de silvicultores o productores forestales para la definición de unidades de estudio: a) categoría 1: silvicultores potenciales, siendo aquellos que cuentan con el recurso forestal maderable, pero no lo aprovechan; b) categoría 2: silvicultores que venden arbolado en pie, éstos poseen recursos forestales que venden a terceras personas que realizan el aprovechamiento; c) categoría 3: silvicultores productores de materias primas forestales, ellos tienen el recurso forestal y lo aprovechan, vendiendo la madera en rollo, y d) categoría 4: silvicultores con capacidad de transformación y comercialización, estos producen madera en rollo y realizan la transformación industrial primaria de la misma y su comercialización.

\subsection{Variables estudiadas para la caracterización del desarrollo de Ejidos y Comunidades Forestales y EFC, así como base para la integración del modelo estratégico}

Se consideraron las siguientes variables relacionadas con el desarrollo forestal sustentable y con la competitividad de ejidos y comunidades forestales:

a) colaboración y competitividad, la cual se refiere al grado de disponibilidad del ejido o comunidad para colaborar e integrarse con 


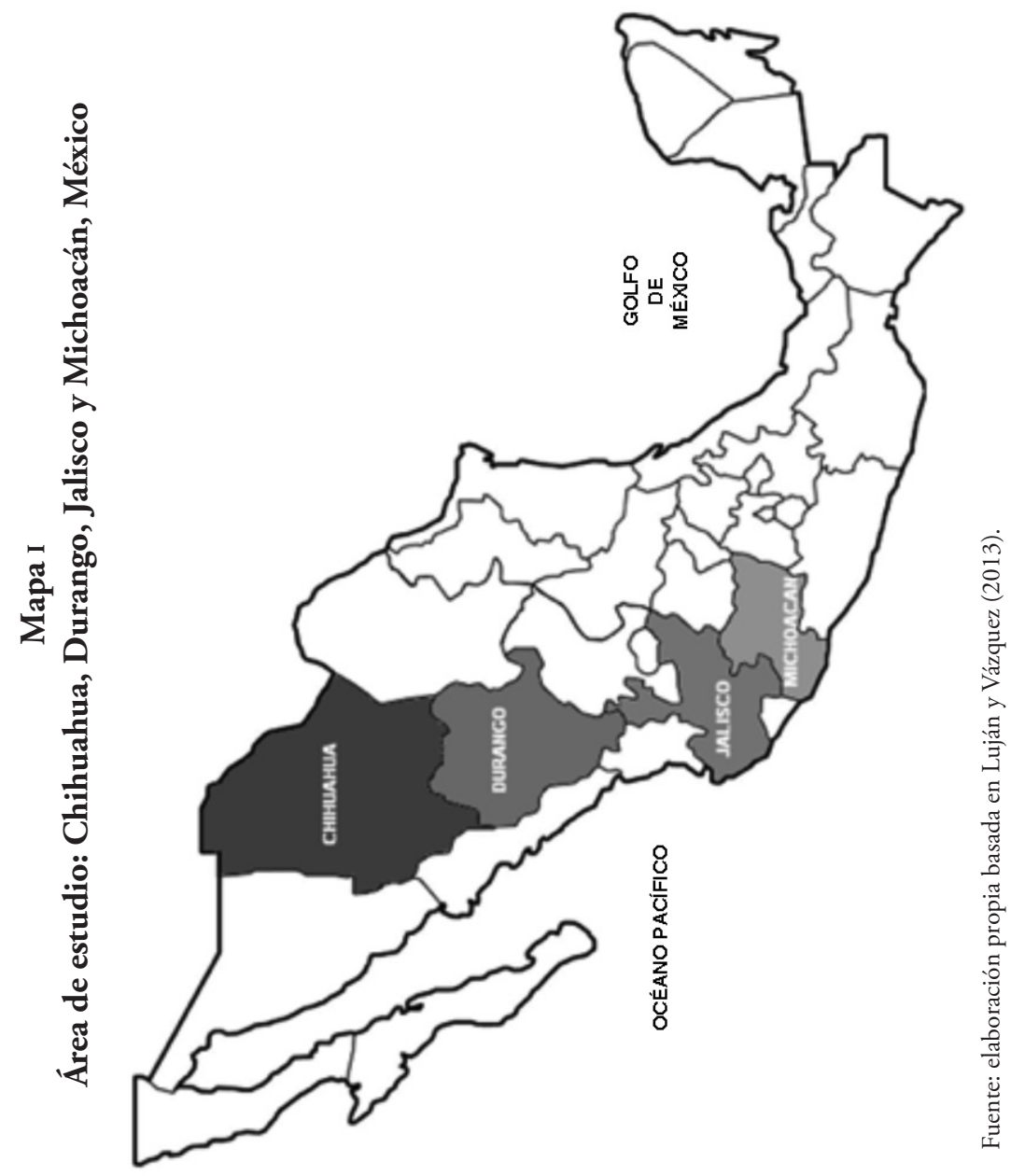


otras instituciones y sumar esfuerzos para lograr mejor competitividad, considerando precio, calidad y ubicación, entre otros;

b) flexibilidad, la cual está relacionada con la cultura organizacional, nivel de integración productiva y la sensibilidad y motivación a los cambios;

c) capacidad de respuesta e innovación, señala el grado en que el ejido o comunidad tiene un nivel de respuesta oportuna o no a la presencia de cualquier factor relacionado con el desarrollo del mismo, y a la vez sustentado en el nivel de desarrollo tecnológico y en la actitud de innovación de los procesos diversos;

d) comercialización, la cual considera planes de comercialización y estrategias de mercado que tiene el ejido/comunidad o EFC.

\subsection{Fuentes de información y unidades de estudio analizadas}

Se consultaron fuentes primarias y secundarias. Las primarias consistieron en encuestas y entrevistas a informantes clave, incluyendo productores forestales ejidales (silvicultores), prestadores de servicios técnicos forestales y expertos nacionales e internacionales. Como fuentes secundarias se consideraron documentos técnicos, y bases de datos, entre otros, relacionados con la temática de estudio.

Para obtener la información de fuentes primarias, se diseñó un cuestionario que incluyó las siguientes secciones: datos de control para identificar y ubicar el ejido/comunidad encuestado, situación actual en relación con el manejo forestal sustentable, colaboración y competitividad, flexibilidad, capacidad de respuesta, innovación y comercialización. Para la determinación de la muestra, se utilizaron los criterios siguientes: las cuatro categorías de productores indicadas en la sección de "Sujetos de estudio", la superficie forestal de predios, el número de predios bajo aprovechamiento forestal y la selección al azar.

Para lo cual se determinó una muestra representativa de 72 ejidos y comunidades forestales de los cuatro estados y las cuatro categorías mencionadas en la tipología de productores. Se aplicó un cuestionario a representantes oficiales para cada ejido involucrado y su categoría de productor correspondiente, incluyendo las variables antes citadas. En los estados de Chihuahua y Durango, por ser los dos estados con mayor superficie y predios en aprovechamiento forestal, el número de unidades de estudio representativas fue de 40, siendo 20 unidades en cada estado (cinco ejidos de cada categoría por estado); para Jalisco y Michoacán, por tener menor superficie y menor cantidad de predios en aprovechamiento forestal que los dos estados anteriores, se definió un tamaño de muestra representativa de 16 unidades de estudio en cada uno de ellos (cuatro ejidos de cada 
categoría). Además se realizaron 20 entrevistas con informantes claves tomadores de decisiones en el contexto nacional e internacional.

\subsection{Sistematización y análisis de la información}

Como un mecanismo para organizar, sistematizar y analizar la información obtenida en el desarrollo del estudio, se procesó en una base de datos diseñada en Excel $^{\oplus}$, en la cual se capturaron las respuestas obtenidas de las encuestas en los cuatro estados, teniendo una respuesta total de $75 \%$, así como la de los informantes claves tomadores de decisiones (expertos nacionales e internacionales) con $70 \%$ de respuesta del total. Se analizó la información en conjunto de los cuatro estados como un sistema, siendo similar el comportamiento de las variables analizadas en los cuatro estados; las respuestas fueron homogéneas.

\subsection{Integración del modelo estratégico para el empoderamiento y la competitividad de la forestería comunitaria}

Este modelo se basó en tres componentes intra e interrelacionados con una visión sistémica. Estos componentes fueron: a) integración del clúster forestal, b) empoderamiento y competitividad, y $c$ ) contexto de la globalización económica.

a) Integración del clúster forestal. Se consideró al sector social representado por la forestería comunitaria (EyCF). Dentro de ésta, como un criterio fundamental para detonar mejores niveles de integración, se tomó como base la tipología de silvicultores de acuerdo al Programa Nacional Forestal (Semarnat-Conafor, 2013b), descrita anteriormente. Adicionalmente, se consideró una tipología de la industria forestal tomada de Banco Interamericano de Desarrollo (BID), Fundación para la Inversión y Desarrollo de Exportaciones (FIDE), y ORGUT Consulting AB (2003), como sigue: 1) la industria primaria, que se ocupa desde la extracción hasta la madera aserrada, y puede incluir algún valor agregado como cepillado y secado; 2) la industria secundaria, que realiza transformación con mayor valor agregado a la madera, normalmente produce partes, piezas, molduras, entre otras; y 3) la industria terciaria, que fabrica productos terminados como pisos, puertas, muebles, artesanías, entre otros.

La integración horizontal/vertical considera las posibles asociaciones entre ejidos forestales o de éstos con empresas privadas u organizaciones no gubernamentales. Asimismo, la visión sistémica favorece la integración del modelo desde la base representada por la forestería comunitaria (ejidos y comunidades forestales=EyCF), incluyendo además al sector empresarial, al público, a organizaciones no gubernamentales y al contexto de la glo- 
balización económica. Además se describen los medios de apoyo necesarios para fortalecer la integración del modelo, como el cambio de paradigmas, educación, capacitación, organización, alianzas y asociaciones, y apoyos gubernamentales.

Dadas las tipologías de silvicultores y de la industria forestal mencionadas, se estableció una vinculación del tipo/categoría del silvicultor con respecto al tipo de la industria que facilita su siguiente nivel de integración, tanto en lo horizontal como en lo vertical. Por ejemplo, en el caso de los silvicultores que venden madera en rollo, el integrarse horizontalmente implica formar un grupo de silvicultores de la misma categoría; ya que como grupo pueden lograr economías de escala que les permitan integrarse verticalmente y pasar al nivel de silvicultores con capacidad de transformación en la industria primaria del sector social o en combinación con el sector privado.

b) Empoderamiento y competitividad. En este segundo componente del modelo, se consideraron los indicadores obtenidos de las variables estudiadas: colaboración y competitividad, flexibilidad, capacidad de respuesta, innovación, y comercialización, así como aspectos del sector forestal relacionados con organización, capacitación, investigación y educación, política institucional, programas de apoyo económico, servicios ambientales y comercialización. El análisis de dichos elementos se realizó por considerar que su interrelación sustenta la definición de factores claves del empoderamiento, como bienestar social, recursos económicos, capital social y humano, tecnología, autogestión y organización.

c) Contexto de la globalización económica. Tomando como base el fortalecimiento de las capacidades de los actores involucrados en la integración horizontal/vertical a nivel de EyCF, por medio del clúster forestal, así como del empoderamiento de la forestería comunitaria, se procedió a identificar acciones estratégicas que permitan transitar desde la forestería comunitaria hacia el ambiente establecido por el contexto de la globalización económica, y lograr que dichos esfuerzos de base actúen en sinergia y se puedan ver como éxitos en este mundo de interconexiones. Además, se estableció la necesidad de identificar ventanas de mercado como oportunidades para el desarrollo de la forestería comunitaria con criterios de productividad, competitividad, y sustentabilidad ambiental. Para esto último, son elementos de apoyo los convenios, acuerdos y tratados comerciales que tiene México con diferentes países (Secretaría de Economía, 2013), los cuales incluyen transferencia de tecnología, procesos de comercialización, recursos financieros internacionales, asesoría de expertos en la materia, y capacitación, entre otros, para que dichas ventanas de mercado sean aprovechadas. 


\subsection{Intra e interconectividad de los componentes del modelo estratégico}

En la integración del modelo, sus componentes están interconectados por medio de procesos permanentes que incluyen el flujo de producción y comercialización de productos forestales maderables y no maderables de lo local a lo internacional, y una continua retroalimentación, así como los procesos de acompańamiento multidimensional y el monitoreo y evaluación para acciones de adaptación y seguimiento en el tiempo.

\section{Resultados y discusión}

\subsection{Perfil del desarrollo de ejidos y comunidades forestales y empresas forestales comunitarias en conjunto en los cuatro estados}

\subsubsection{Competitividad y colaboración para integración de ejidos y comuni-} dades forestales en la apertura de la economía de mercados

En la competitividad es donde los ejidos y comunidades forestales enfrentan el mayor reto. Ésta se ve afectada por los altos costos de producción en las actividades de extracción y transformación de productos forestales, siendo el transporte el concepto que más impacta por sus altos costos $(60 \%)$. De igual manera, se tienen limitaciones relacionadas con el equipo para la construcción y mantenimiento de caminos, lo cual eleva los costos de producción y, por lo tanto, afecta el nivel de competitividad de los EyCF. En la percepción de los productores forestales, los precios bajos de compra son el principal efecto de la apertura de mercados. Esto se debe a los precios reducidos de los productos importados en comparación con los locales (gráfica I).

Adicionalmente, un comportamiento identificado por los productores forestales es el grado de influencia de tres factores relacionados con la competitividad de los ejidos y comunidades forestales: precio, calidad y ubicación (gráfica II). Se observa que para la categoría 2 el factor que más afecta es la ubicación, y para la 3 y 4 la calidad.

En relación con la colaboración, los EyCF reconocen la insuficiencia de una visión empresarial a corto, mediano y largo plazo; sin embargo, identifican que deben de considerar con más profundidad las bondades de esta acción de colaboración y poder aplicarlo en su realidad. 


\section{Gráfica I}

Percepción de ejidos y comunidades forestales acerca de los efectos de la apertura comercial

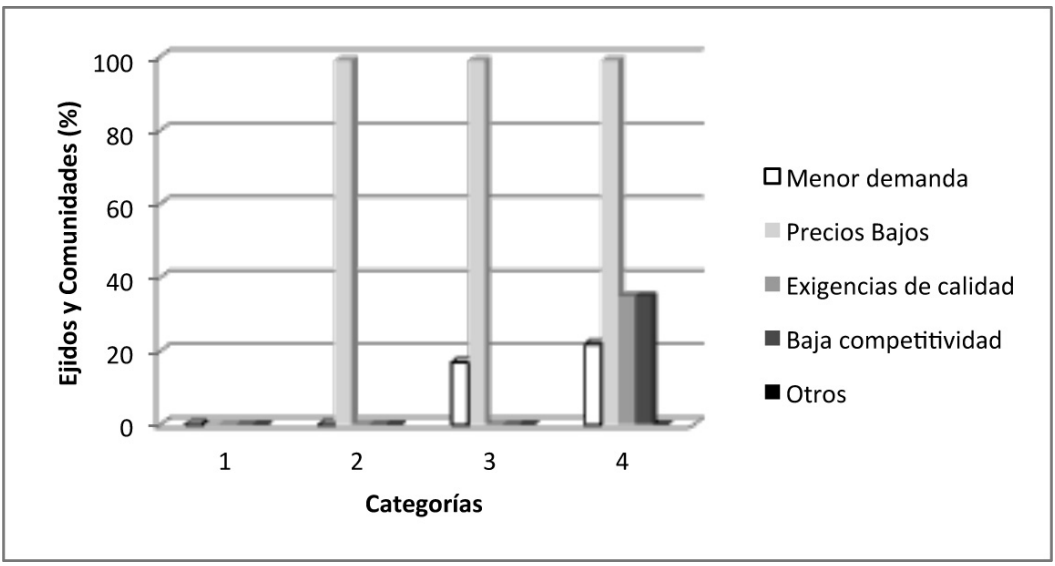

Fuente: elaboración propia con datos tomados en ejidos y comunidades forestales en estudio.

\section{Gráfica II}

Factores que afectan la competitividad de los productos forestales en los ejidos y comunidades forestales

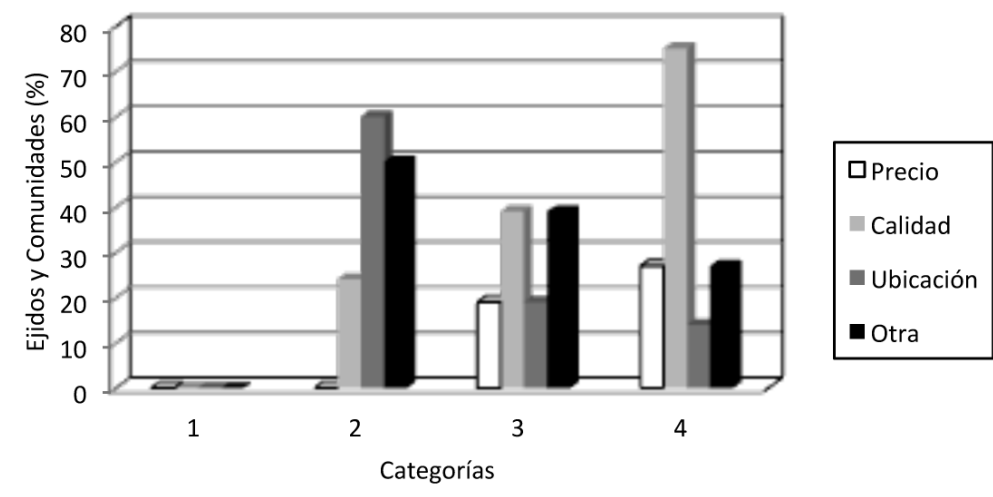

Fuente: elaboración propia con datos tomados en ejidos y comunidades forestales en estudio.

Comercialización. El principal lugar de venta de los productos maderables de los EyCF es la región o los propios ejidos y comunidades, de ahí que exista la percepción de que los principales competidores, de inicio, son los mismos ejidos y comunidades. A la vez, se detectó que no cuentan con planes de comercialización en los EyCF, lo que hace necesario forta- 
lecer la investigación de mercados, así como la asesoría y preparación para entender estos aspectos y tomar decisiones más adecuadas.

Adicionalmente, como se observa en la gráfica III, en las tres primeras categorías predomina el proceso productor-intermediario-consumidor final, no así, en la cuarta categoría donde es más frecuente el intercambio comercial con los consumidores mayoristas, por lo que no existe intercambio comercial directo entre los productores y los consumidores, sino a través de intermediarios, lo que refleja la necesidad de promover mayor integración de la cadena productiva forestal, incluyendo el establecimiento y consolidación de clústeres, alianzas o uniones de ejidos forestales, a través de la promoción de figuras asociativas.

\section{Gráfica III \\ Proceso de comercialización de los ejidos y comunidades forestales según los canales de comercialización}

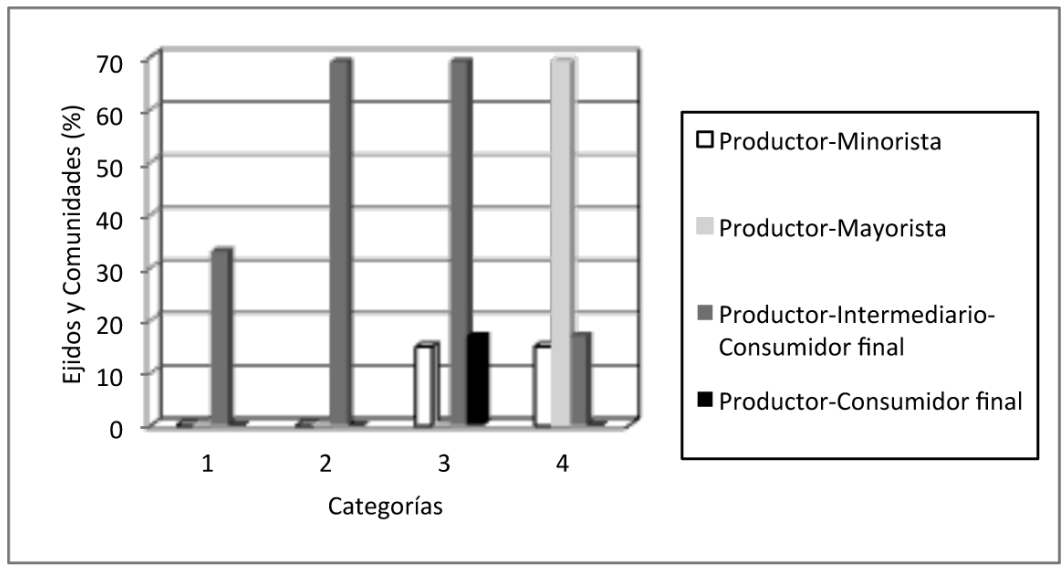

Fuente: elaboración propia con datos tomados en ejidos y comunidades forestales en estudio.

Flexibilidad, capacidad de respuesta e innovación. Los EyCF muestran algunas fortalezas relevantes que pueden favorecer su capacidad de respuesta, flexibilidad e innovación; éstas son la riqueza de sus recursos forestales y sus atractivos turísticos, la toma de decisiones basada en mayoría de votos, apoyada en sus estructuras tradicionales de organización y con participación comunitaria, y la creciente toma de conciencia de la necesidad de preservar sus recursos naturales. También manifestaron interés en diversificarse en actividades tales como ecoturismo, servicios ambientales, acuacultura y transformación de productos maderables. A la vez, los resultados indican que donde el grado de organización de las comunidades forestales es mayor (categorías 3 y 4 ) es 
también donde se presenta mayor flexibilidad y capacidad de respuesta e innovación tecnológica.

En suma, considerando el comportamiento del perfil común en los cuatro estados de la república mexicana, se identifica que los EyCF no son competitivos en el mercado internacional; siendo notorio que hay una pérdida paulatina y creciente de sus alcances en el mercado en general, debido a los altos costos de producción, bajos niveles de capacitación, deficiente organización, ausencia de planeación y seguimiento en el mediano y largo plazo, y a la carencia de asociaciones adecuadas que permitan manejar sus empresas con un sentido de rentabilidad.

\subsection{Propuesta del modelo estratégico participativo de integración borizontal y vertical para el empoderamiento y la competitividad de la forestería comunitaria}

Se generó la propuesta del modelo estratégico participativo de integración horizontal y vertical para el empoderamiento y la competitividad de la forestería comunitaria (figura I), considerando como base y capacidad de respuesta el perfil descriptivo de EyCF/EFC (sección anterior) y la necesidad de establecer una estrategia de competitividad con visión holística y encaminada a lograr un desarrollo sustentable y competitivo, relacionada con el principio de la "competitividad sistémica", en coincidencia con lo indicado por Villarreal (2002); además de la necesidad de considerar que los clústeres de las EFC continúan emergiendo en diferentes lugares en el mundo, como lo establecen diversos autores (Cortave, 2003; Gill, 2002; Nolan, 2001; Scherr et al., 2003), así como los enfoques alternativos de desarrollo que incluyen el "empoderamiento" y la relevancia de las comunidades organizadas (Friedmann, 1992; Hirschman, 1993; Redclift, 1987).

El modelo incluye, en primer término, la estrategia básica de integración o clúster forestal, lo cual, a su vez, sustenta el empoderamiento y la estrategia en el contexto de la globalización económica (figura I). En la búsqueda de mayor capacidad de respuesta en el desarrollo de la forestería comunitaria sustentable y empresas forestales comunitarias, y de mayores niveles de competitividad, la estrategia integral básica planteada fue la integración horizontal/vertical, considerando los diferentes tipos/categorías de productores forestales e industria forestal, y participación de empresas forestales sociales y privadas, lo cual representa un medio para lograr el fin antes mencionado. Por ello, a continuación se discuten cada uno de los componentes estructurales del modelo estratégico participativo. 


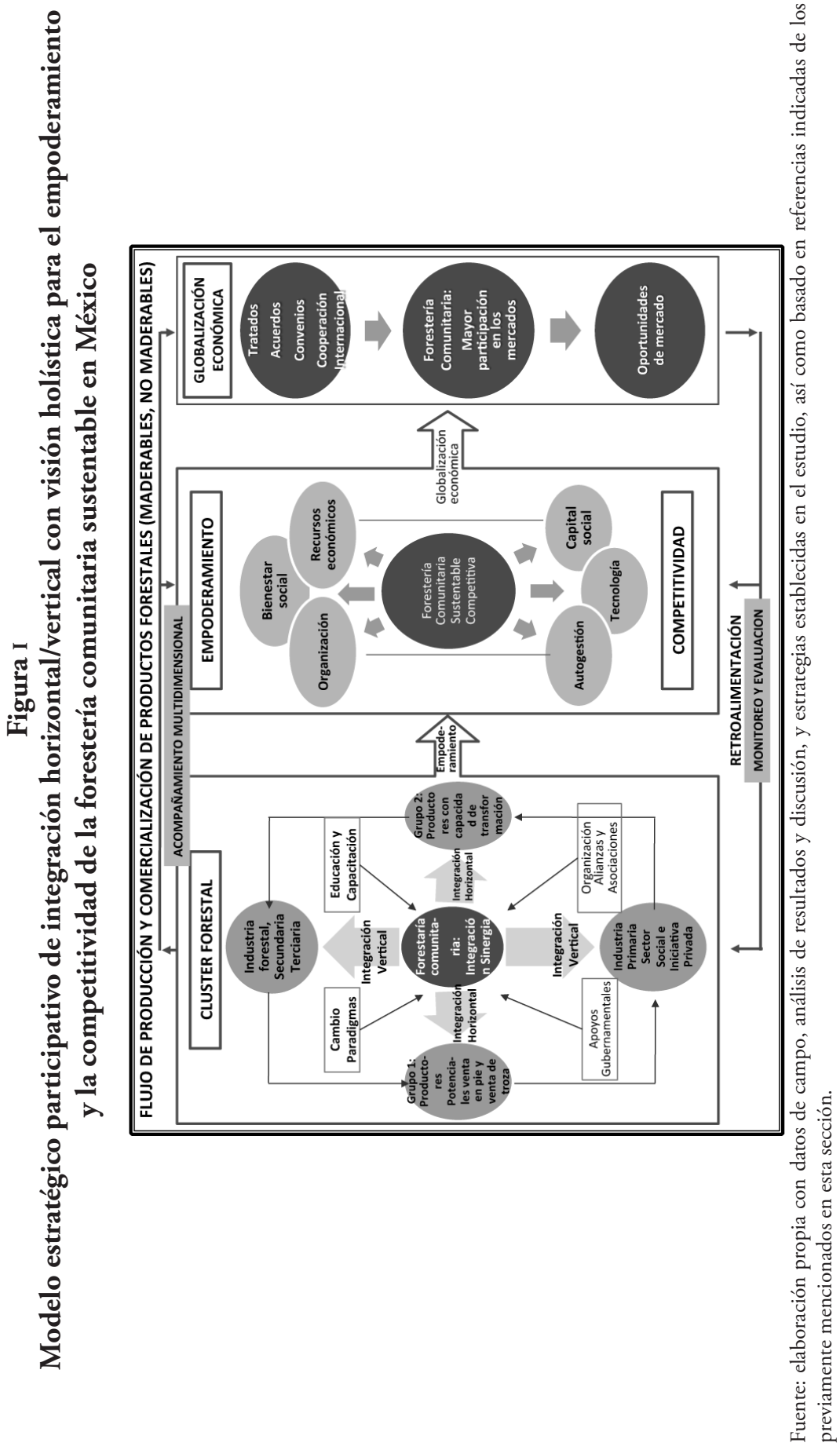




\subsubsection{Clíster forestal: integración horizontal/vertical y visión sistémica de la estrategia básica del modelo.}

El modelo estratégico consideró que cada ejido forestal, independientemente de su grado de desarrollo o de la cantidad de recursos, no continúe comercializando sus productos en forma aislada, sino asociándose con los demás EyCF e inclusive con propietarios de predios particulares de la misma región. Además, propuso agregar valor a sus materias primas, a través de empresas integradas también en forma vertical, de modo que puedan aprovechar las economías de escala que sólo son factibles mediante la asociatividad (figura I).

Es evidente que lograr la integración entre los actores de la actividad forestal de una región no es sencillo bajo los paradigmas actuales, caracterizados por un comportamiento individualista y visión a corto plazo de los participantes en cada eslabón de la cadena productiva; por lo que para lograr que la actividad forestal sea competitiva en el contexto de la globalización económica, deben de fortalecer sus cambios para un interés común, máximos beneficios y largo plazo.

Por ello, de acuerdo con las tipologías (categorías para silvicultores e industria forestal descritas en la sección de metodología), se definió como grupo 1 de silvicultores al integrado por los productores potenciales (tipo 1 ), silvicultores que venden en pie (tipo 2) y silvicultores productores de materias primas forestales (tipo 3).

De la misma manera se definió el grupo 2 de silvicultores a los que tienen capacidad de transformación y comercialización (tipo 4) y que ocupan el lugar de la industria secundaria y terciaria. Por lo que fue necesario establecer una vinculación del tipo de silvicultor, con respecto a la clase de industria con que se relaciona, con el fin de visualizar la organización en figuras asociativas más acordes a su nivel de producción, y que a su vez dichas figuras les ayuden a detonar su desarrollo productivo y avanzar en su nivel de integración y competitividad.

En consecuencia, la dinámica de integración establecida en este modelo estratégico indica que es recomendable que de manera inicial en $e l$ grupo 1 se favorezca la integración en dirección horizontal que les permita fortalecerse y sumar esfuerzos. Dicho grupo, por sus características, debe aspirar al nivel de la industria primaria. Por su parte el grupo 2 también debe favorecer su integración horizontal, pero con la visión de transformarse en industria secundaria y terciaria.

Por tal motivo, para el éxito futuro de esta estrategia de integración se consideraron, entre otras, las siguientes acciones: sensibilización e inducción al cambio de paradigmas, utilización de apoyos gubernamentales, educación y capacitación, y organización de alianzas y asociaciones. 
Particularmente, en referencia al cambio de paradigmas, estos pueden surgir de la adaptación de experiencias ya vividas en otros países, como pueden ser: adquirir y operar en forma común mediante esquemas de cooperación y administración, y el uso de maquinaria y equipos de extracción e industrialización de tecnología más avanzada para procesar la madera de varios EyCF y de otros pequeños propietarios.

Para el caso de educación y capacitación, será básico lograr niveles de vanguardia y fomentar una capacitación sistemática y continua con un plan a largo plazo. En relación a la organización por medio de alianzas y asociaciones, se requiere establecer y operar figuras asociativas con criterio empresarial que permitan establecer y consolidar empresas forestales comunitarias, y por ende, disminuir costos de producción, lograr un mejor balance económico, realizar operaciones directas de sus productos, ser una fuente de autofinanciamiento, y comercialización de productos, entre otros.

Por último, se propone aprovechar los programas de apoyo gubernamental, como el Programa Nacional Forestal 2013-2018 (Conafor, 2013) y otros, para fomentar la integración horizontal y vertical de cadenas productivas, el desarrollo empresarial y el fortalecimiento del periodo de acompañamiento multidimensional (técnico, sociocultural, administrativo, organizacional, financiero, mercados) brindando asistencia técnica, económica y administrativa, a través de una red de asesores especializados y certificados que coadyuven a la integración en ambos sentidos para lograr que el clúster forestal sea competitivo.

\subsubsection{Empoderamiento y competitividad}

Un componente estructural completamente vinculado y articulado al clúster forestal es el relacionado con el empoderamiento y la competitividad. Éste es uno de los elementos fundamentales para fortalecer las capacidades de respuesta necesarias para el desarrollo y competitividad de la forestería comunitaria ante la globalización económica. Entendiéndose el empoderamiento como el autofortalecimiento, el autocontrol, la decisión propia, la autogestión, la vida digna con valores, y la capacidad para luchar por su derechos, e independencia, entre otros.

De acuerdo con el Banco Mundial (2004), existen cuatro elementos comunes que interactúan en sinergia en los procesos de empoderamiento: acceso a la información, inclusión y participación, responsabilidad o rendición de cuentas y capacidad local de organización. Esto sustenta que el modelo propuesto integre a un conjunto de factores resultantes del empoderamiento, como recursos económicos, capital social y humano, tecnología, autogestión, organización y bienestar social. Lo anterior, se 
reflejará en su nivel de competitividad que les permita mayor participación con éxito en los mercados nacionales e internacionales.

\subsubsection{Globalización económica}

Referido al tercer componente estructural del modelo, y también de manera articulada a los dos anteriores, después de sustentar la integración horizontal/vertical del clúster forestal, así como el empoderamiento y competitividad de los actores involucrados, es importante referir que la globalización exige a EyCF/EFC ser cada vez más productivos y competitivos; por ello, los componentes de la integración del clúster forestal y el empoderamiento deben enlazarse al mundo de la apertura comercial a través de ventajas competitivas sostenibles basadas en el desarrollo de habilidades y capacidades (tecnología, investigación e innovación), y ventajas comparativas, basadas en los costos de disponibilidad (materias primas, reducción de costos y cercanía). Para ello, existen en el contexto internacional ventanas de mercado, como señala Gabriela de la Mora (2003) en su estudio "El comercio internacional y el sector forestal en México", mismas que representan oportunidades para el desarrollo de la forestería comunitaria con criterios de productividad, competitividad y sustentabilidad ambiental (Chapela, 2011).

Estas ventanas de mercado deben de ser aprovechadas mediante el impulso de convenios y de acuerdos basados en los diferentes tratados comerciales que tiene México con diferentes países, en la transferencia de tecnología, en los recursos financieros internacionales, en la asesoría de expertos en la materia, y en la capacitación, entre otros aspectos (Secretaría de Economía, 2013). Además, una forma de participar en los mercados es conformar empresas integradoras de exportación, mediante la identificación de empresas pequeñas y medianas que fabrican un producto homogéneo e interesarlas en agruparse para incrementar sus volúmenes e incursionar con mejores condiciones en el mercado de exportación (terreno común).

\subsubsection{Intra e interconectividad de los componentes estructurales del modelo estratégico}

La integración del modelo establecido incorpora la necesidad de que sus tres componentes sean abordados con visión holística y con criterio de "competitividad sistémica" (Villarreal, 2002), como integrar el clúster forestal, lograr su empoderamiento y luego incidir mejor en los mercados en el contexto de la globalización económica. Para ello, estos tres componentes deben concebirse intra e interconectados, a través de los meca- 
nismos que constituyen el flujo de producción y comercialización de productos forestales maderables y no maderables, y su respectivo proceso de retroalimentación, acompañamiento multidimensional y monitoreo y seguimiento. En su conjunto, estos mecanismos llevarán al modelo a un proceso de adaptación que permitirá lograr, a través del tiempo y a largo plazo, la consistencia y dinámica que requiere para que la forestería comunitaria avance hacia un empoderamiento y competitividad con visión de sustentabilidad (figura I).

\section{Conclusiones}

La globalización económica es irreversible y la forestería comunitaria en México no puede excluirse de este proceso al tener mayor exigencia en el campo de la competitividad; por lo tanto, lo que procede para mejorar los beneficios socioeconómicos y ambientales es buscar ser más productivos y competitivos, ya que entre los principales efectos de la globalización económica que han tenido los EyCF/EFC se encuentran: precios bajos en sus productos por la reducción de precios de los productos de la madera importados, la disminución de la demanda y la exigencia de calidad de lo que ellos producen.

A partir del análisis de la competitividad y colaboración, diversificación productiva, flexibilidad, capacidad de respuesta, comercialización e innovación se detectaron impactos no favorables en rentabilidad, cultura administrativa y organizacional, infraestructura para el aprovechamiento y transformación, y en aspectos ecológico ambientales, que han limitado la capacidad de respuesta de EyCF/EFC a las demandas de la apertura económica. Este bajo nivel de competitividad ante los efectos de la globalización puede verse como una área de oportunidad, para lo que en principio, es necesario impulsar acciones orientadas a lograr un cambio de paradigma en los productores forestales que sensibilice y facilite la adopción de esta estrategia básica, siendo trascendente la educación y la capacitación. De la misma manera, los productores forestales deben invertir recursos y esfuerzos en conseguir mayores niveles de integración horizontal y vertical y mayor competitividad, para lo cual deben adoptar una lógica organizativa empresarial, además de conocimientos tecnológicos modernos y alianzas entre comunidades y empresas.

En respuesta a esta condición a corto, mediano y largo plazo, se establece la propuesta del modelo integral estratégico participativo con visión holística para lograr el empoderamiento y la competitividad de la forestería comunitaria sustentable en México (figura I). Este modelo presenta bondades tales como la suma de esfuerzos para mejores condiciones de comercialización, acceso a mercados y tecnología, búsqueda de mayores recursos 
financieros y niveles de competitividad, mayor capital social y humano, capacidad organizativa y autogestión, recursos económicos, procesos de sinergia como resultado del interés común y compromisos adquiridos por medio de la creación y funcionamiento de figuras asociativas.

El modelo integral estratégico participativo contrasta con el modelo tradicional del desarrollo forestal comunitario y las EFC, en el cual predominan la visión a corto plazo y la acción aislada e individual; de tal manera que el modelo propuesto ofrece flexibilidad, accesibilidad para su adopción, visión sistémica de largo plazo y la suma de esfuerzos basados en un bienestar común.

El modelo fue validado por EyCF involucrados de los cuatro estados, por medio de la presentación de su estructura y bondades, el mismo que fue ratificado por los participantes, dada la necesidad de encontrar y aplicar estrategias de producción competitiva y desarrollo forestal sustentable en el largo plazo, ante los cambios continuos del entorno en general, y en particular ante los retos que han surgido en relación a la globalización económica; sin embargo, aún cuando no es simple la apropiación y compromiso de los procesos comunitarios por los silvicultores/productores es necesario promover cambios de paradigmas, así como fomentar las bondades de la asociatividad para efectos de hacer frente a la globalización.

Una de las principales limitaciones del estudio fue que se encontró escasa aplicación de sistemas de control y seguimiento con información registrada en forma sistemática en EyCF/EFC relacionada con sus procesos de desarrollo. Por consiguiente, es necesario impulsar sistemas de control y seguimiento en EyCF/EFC para lograr mejores toma de decisiones, de forma oportuna y con mayor sustento.

De la misma manera, es relevante continuar realizando estudios estructurales y operacionales relacionados con el modelo planteado en otros estados de la república mexicana que coadyuven al fortalecimiento del modelo propuesto a un nivel más amplio y aplicado en México a nivel regional, local y estatal en el largo plazo. Adicionalmente, existe la necesidad de promover en el futuro mayor integración de la cadena productiva forestal, incluyendo el establecimiento y consolidación de clúster, alianzas o uniones de ejidos forestales, a través de la promoción de figuras asociativas haciendo uso de convenios.

En la economía global, los ejidos y comunidades podrán competir con la efectividad empresarial, impulsando su conversión en empresas y la estrategia de asociatividad, como lo plantea el modelo con visión holística motivo del presente estudio. 


\section{Bibliografía}

Alviar, Mauricio, Lilia Domínguez-Villalobos y Raul O’Ryan (2007), Introducción a la economía ambiental, McGraw-Hill-Interamericana de España, Madrid.

Antinori, Camille y David Bray (2005), “Community forest enterprises as entrepreneurial firms: economic and institutional perspectives from Mexico", World Development, 33 (9), Elsevier Ltd, Great Britain, pp. 1529-1543.

вм (Banco Mundial) (2004), "Pensando en Voz Alta V Primavera 2004. Innovadores estudios de caso sobre instrumentos participativos", Latin America and the Caribean Region-Civil Society TeamOficina Regional de América Latina y el Caribe-Banco Mundial, Washington, <http://www-wds.worldbank.org/servlet/WDSContentServer/WDSP/IB/2004/11/03/000160016_200411031049 44/Rendered/PDF/303320SPANISH0Thinking0out0loud0V. pdf>, 9 de enero de 2008.

BID-FIDE-Consulting AB (Banco Interamericano de Desarrollo-Fundación para la Inversión y Desarrollo de Exportaciones-Consulting AB) (2003), "Servicios de consultoría para la elaboración de estrategias para negocios forestales sostenibles, Honduras", ORGUT Consulting $\mathrm{AB},<\mathrm{http}$ //www.iadb.org/regions/re2/forestal/Documentos/Documento\%20Conceptual\%20I.pdf>, 11 de enero de 2010.

Bonita, Manuel, Fernando Correa, Pertti Veijalainen y Harry Ahveninen (2002), "Forest clusters: a competitive model for Latin America", Inter-American Development Bank, Sustainable Development Department, Environment Division, Informe final, 2004, Washington, http://www.iadb.org/sds/doc/ENV-IDBForestClústers.pdf, 11 de julio de 2008 .

Bray, David, Leticia Merino-Pérez, Patricia Negreros-Castillo, Gerardo Segura-Warnholtz, Juan Manuel Torres-Rojo y Henricus Vester (2003), "Mexico's community-managed forests: A global model for sustainable landscapes?”, Conservation Biology, 17 (3), Society of Conservation Biology, Washington, pp. 672-677.

Bray, David y Leticia Merino-Pérez (2004), Los bosques comunitarios de México: logros y desafíos, Editora Infagón, México. 
Colchester, Marcus (2003), "Bridging the gap: Challenges to community forestry networking in Indonesia", Learning from International Community Forestry Networks, Cifor, pp.1-34, http://www.cifor. cgiar.org/publications/pdf_files/CF/Indonesia_CF.pdf., 10 enero 2013.

Conafor (Comisión Nacional Forestal) (2013), Estrategia de Incremento a la Producción y Productividad Forestal Nacional 2013-2018, Conafor, Guadalajara.

Cortave, Marcedonio (2003), La experiencia de ACOFOP en Petén, Guatemala: Un proceso arduo de gestión política, Centro de Derecho Ambiental y de los Recursos Naturales-Coordinadora IndígenaCampesina de Agroforestría Comunitaria, San José.

Chapela, Gonzalo (2011), Competitividad de las empresas sociales forestales en México, Universidad Autónoma Chapingo-Consejo Civil Mexicano de Silvicultura Sostenible, A. C., México.

Flores, Rogelio, Enrique Serrano, Víctor Palacio y Gonzalo Chapela (2007), "Análisis de la industria de la madera aserrada en México", Madera y Bosques, 13 (1), Instituto de Ecología, Xalapa, pp. 47-59, http://www.redalyc.org/articulo.oa?id=61713105, 20 de abril 2010.

Friedmann, John (1992), Empowerment: The politics of alternative development, Blackwell Publishers, Oxford.

Galicia, Leopoldo, Leticia Gómez-Mendoza, Alma Mendoza-Ponce y Alba Zarco-Arista (2009), "Análisis, priorización de alternativas y plan estratégico para mejorar la competitividad del manejo del agua, conservación de la biodiversidad y los recursos forestales de los bosques templados de México", Informe Técnico, mayo a noviembre de 2008, Fondo Mexicano para Conservación de la Naturaleza (FMCN) y United States Agency for Internacional Development (USAID), Universidad Nacional Autónoma de México, México.

Gill, Ian (2002), "The first nations reclaim a temperate rain forest", Sustainable solutions: Building assets for empowerment and sustainable development, Ford Foundation, New York, pp. 81-85. 
Hirschman, Albert (1993), Getting ahead collectively: grassroots experiences in Latin America, VA-Inter-American Foundation, Arlington.

Klooster, Dan (2003), "Campesinos and mexican forest policy during the twentieth century", Latin American Research Review, 38 (2), Latin American Studies Association-University of Texas, Austin, pp. 94-126.

Labandeira, Xavier, Carmelo León y María Vázquez (2007), Economía Ambiental, Prentice Hall- Person Educación, Madrid.

Linda, Hunter, James Markusen y Thomas Rutherford (1991), "Trade liberalization in a multinational-dominated industry: a theoretical and applied general-equilibrium analysis", Working Paper 3679, National Bureau of Economical Research, Cambridge.

Luján, Concepción y Susana Vázquez (2013), Mapa del área de estudio, $<$ http://paraimprimir.org/mapa-de-la-republica-mexicana-sinnombre-para-imprimir/>, noviembre de 2013.

Mora, Gabriela de la (2003), "El comercio internacional y el sector forestal en México", Consejo Civil Mexicano de Silvicultura Sostenible, A. C. México, <http://www.ccmss.org.mx/modulos/biblioteca_consultar.php?folio=25>, 10 de enero 2008 .

Morsello, Carla (2006), "Company-community non-timber forest product deals in the Brazilian Amazon: A Review of opportunities and problems", Forest Policy and Economics, 8 (4), Elsevier Editorial System, Philadelphia, pp. 485-494.

Nolan, Timothy (2001), "Community based forest management: Commercial harvesting of the rainforest of Indonesia", The International Forestry Review, 3 (3), The Commonwealth Forestry Association, London, pp. 231-235.

Pagdee, Adcharaporn, Kim Yeon-Su y Jim Daughert (2006), "What makes community forest management successful? A meta-study from community forests throughout the world", Society and Natural Resources, vol. 19, International Association for Society and Natural Resources, Madison, Wisconsin, pp. 33-52. 
Porter, Michael (1990), The competitive advantage of nations, Mac Millan, London.

Redclift, Michael (1987), Sustainable development: exploring the contradictions, Routledge, Nueva York.

Sabogal, César, Wil de Jong, Benno Pokorny y Bastiaan Louman (2008), Manejo forestal comunitario en América Latina. Experiencias, lecciones aprendidas y retos para el futuro, Cifor, Bogor, Indonesia.

Secretaría de Economía (2013), "Tratados y acuerdos firmados por México", Secretaría de Economía, México, <http://www.economia.gob.mx/comunidad-negocios/comercio-exterior/tlc-acuerdos>, 22 de septiembre de 2013.

Semarnat (Secretaría de Medio Ambiente y Recursos Naturales)-Conafor (Comisión Nacional Forestal) (2001), "Programa Estratégico Forestal para México 2025 (PEF)”, Informe Final versión 2.1., Semarnat-Conafor, México.

Semarnat (Secretaría de Medio Ambiente y Recursos Naturales)-Conafor (Comisión Nacional Forestal) (2004), Anuario Estadístico de la Producción Forestal, Semarnat-Conafor, México, <http://148.223. 105.188:2222/snif_portal/index.php?option=com_content\&tas $\mathrm{k}=\mathrm{view} \& \mathrm{id}=33 \&$ Itemid=36>, 8 de enero de 2010 .

Semarnat (Secretaría del Medio Ambiente y Recursos Naturales) (2011), Anuario Estadístico de la Producción Forestal, Semarnat, México.

Semarnat (Secretaría de Medio Ambiente y Recursos Naturales)-Conafor (Comisión Nacional Forestal) (2013a), "Propuesta de actualización programa estratégico forestal para México 2025”, vol. 4, mayo 2013, Semarnat-Conafor, México.

Semarnat (Secretaría de Medio Ambiente y Recursos Naturales)-Conafor (Comisión Nacional Forestal) (2013b), "Reglas de operación del Programa Nacional Forestal 2013”, Diario Oficial de la Federación, 8 de marzo de 2013, Secretaría de Gobernación, México.

Scherr, Sara, Andy White y David Kaimowitz (2003), A new agenda for conservation and poverty reduction: Making forest markets work for 
low-income producers, Forest Trends-Center for International Forestry Research, Washington.

Smith, Bob y Víctor Cossio (2008), "Competitiveness of forest products at global markets; with particular emphasis on tropical forest products and on small and medium scale producers", The Retail Market Review, Ofgem, New York, pp.1-38.

Stoian Dietmar y Jason Donovan (2008), "Capacidades empresariales para el desarrollo de empresas forestales comunitarias", en Sabogal, César, Wil de Jong, Benno Pokorny y Bastiaan Louman (eds.), Manejo forestal comunitario en América Latina. Experiencias, lecciones aprendidas y retos para el futuro, Centro para la Investigación Forestal (Cifor), Bogor, Indonesia, pp. 115-153.

Vidal, Natalia y Gabriela Donini (2004), "Promising business models for community-company collaboration in Brazil and Mexico", Forest Trends, Forest Trends Association, Washington, pp. 1-29.

Villarreal, René y Rocío Ramos (2002), México competitivo 2020: un modelo de competitividad sistémica para el desarrollo, Océano, México.

Recibido: 28 de septiembre de 2013. Reenviado: 24 de febrero de 2014. Aceptado: 13 de julio de 2014.

Concepción Luján-Álvarez. Mexicano. Es doctor (Ph.D.) en planeación estratégica participativa, desarrollo regional, desarrollo sustentable y desarrollo forestal comunitario por la New Mexico State University. Actualmente es profesor-investigador de la Facultad de Ciencias Agrícolas y Forestales de la Universidad Autónoma de Chihuahua. Ha sido distinguio con el Premio al Mérito Nacional Forestal, es Miembro de la Academia Nacional de Ciencias Forestales, A. C., Miembro del Sistema Nacional de Investigadores, Miembro Red Internacional de Desarrollo Forestal Sustentable, Miembro Consejo Asesor del Centro Nacional Negocios Forestales Conafor. Su línea de investigación es el desarrollo forestal sustentable, incluyendo aspectos como desarrollo forestal comunitario, empresas forestales comunitarias, planes de negocios forestales, evaluación del desarrollo forestal sustentable, entre otras. Entre las últimas publicaciones destacan: "Estrategia multidimensional para el desarrollo forestal sustentable en el ejido forestal Tetahuichi, Chihuahua, México", Revista 
Forestal Baracoa, 32 (2), Instituto de Investigaciones Forestales de Cuba, La Habana, pp. 11-17 (2013); Desarrollo de la Asociación Regional de Silvicultores "Baja Tarahumara", A. C., Urique, Chihuahua, Mexico. Plan de negocios y empresa social forestal, Conacyt-Conafor-Universidad Autónoma de Chihuahua, Chihuahua, 97 pp. (2014); La competitividad de las empresas sociales forestales en México: De la PROFORTARAH a la certificación: Las Empresas sociales forestales de Chihuahua: Los ejidos: La Trinidad y Aboreachi. Chihuahua, Universidad Autónoma de Chapingo, Chapingo, en prensa, 118 pp., (2013). En coautoría: "Evaluation system proposal for sustainable forestry development in Mexico", International Journal Forest, Soil and Erosion, 3 (4), Ministry of Culture and Islamic Guidance, I. R., Irán, pp. 134-140 (2013); "Planeación estratégica participativa para el desarrollo sustentable del ejido Baquiriachi, Chihuahua, México", Revista Forestal Baracoa, 32 (2), Instituto de Investigaciones Forestales de Cuba, La Habana, pp. 11-17 (2013); "Feasibility of electricity generation form sawmill biomass residues in the north of Mexico", Forest Bioenergy 2010, FINBIO-The Bioenergy Association of Finland, Finlandia, pp. 255-264 (2010); "Efecto del manejo forestal en la diversidad y composición arbórea de un bosque templado del Noroeste de México", Revista Chapingo, XIX (2), Universidad Autónoma de Chapingo, Chapingo, pp. 147-157 (2013).

Jesús Miguel Olivas-García. Mexicano. Doctor (Ph.D.) en ciencias forestales por la University of Nebrask-Lincoln. Actualmente es profesorinvestigador de tiempo completo de la Facultad de Ciencias Agrícolas y Forestales en la Universidad Autónoma de Chihuahua, donde es responsable del Cuerpo Académico Consolidado UACH-CA-15 "Agroforestería Sustentable". Su línea de investigación actual es desarrollo forestal sustentable y aborda principalmente temas relacionados con el uso y manejo sustentable de recursos forestales del semidesierto chihuahuense y de bosques de clima templado-frío, así como la planeación y evaluación del desarrollo forestal sustentable. En los últimos ocho años ha desarrollado trabajos de auditoría y revisión de reportes de evaluación de la certificación de buen manejo forestal y Cadena de Custodia, bajo los principios del Forest Stewarship Council. Entre sus últimas publicaciones destacan: "Evaluation system proposal for sustainable forestry development in Mexico", International Journal Forest, Soil and Erosion, 3 (4), Ministry of Culture and Islamic Guidance, I. R., Irán, pp. 134-140 (2013); "Planeación estratégica participativa para el desarrollo sustentable del ejido Baquiriachi, Chihuahua, México", Revista Forestal Baracoa, 32 (2), Instituto de Investigaciones Forestales de Cuba, La Habana, pp. 11-17 (2013); "Modelo para estimar el peso de piñas de sotol (Dasylirion spp.) en la Región de Coyame, Chihuahua", Revista Internacional de Contaminación Ambien- 
tal, 29 suplemento, Universidad Nacional Autónoma de México, México, págs. 1:300, (2013). En coautoría: "Estrategia multidimensional para el desarrollo forestal sustentable en el ejido forestal Tetahuichi, Chihuahua, México", Revista Forestal Baracoa, 32 (2), Instituto de Investigaciones Forestales de Cuba, La Habana, pp. 25-30 (2013); "Efecto del manejo forestal en la diversidad y composición arbórea de un bosque templado del Noroeste de México", Revista Chapingo, XIX (2), Universidad Autónoma de Chapingo, Chapingo, pp. 147-157 (2013).

Hilda Guadalupe González-Hernández. Mexicana. Maestra en ciencias en agronegocios, Universidad Autónoma de Chihuahua. Actualmente es directora del proyecto nacional: "Transformar el manejo de bosques de producción comunitarios ricos en biodiversidad mediante la creación de capacidades nacionales para el uso de instrumentos basados en el mercado". Programa de las Nacionales Unidas-Conafor. Su línea de investigación actual es desarrollo forestal comunitario y aborda principalmente temas relacionados con el desarrollo de las empresas forestales comunitarias en México, evaluación del desarrollo forestal sustentable y la planeación y evaluación del desarrollo forestal sustentable. Entre sus últimas publicaciones destacan, en coautoría: Forests in the global balance: changing paradigms, IUfro Special project on World Forests, Society and Enviroment (IUfro-WFSE), Helsinki-Finlandia, 318 pp. (2005); "Estrategia multidimensional para el desarrollo forestal sustentable en el ejido forestal Tetahuichi, Chihuahua, México", Revista Forestal Baracoa, 32 (2), Instituto de Investigaciones Forestales de Cuba, La Habana, pp. 25-30 (2013); "Planeación estratégica participativa para el desarrollo sustentable del ejido Baquiriachi, Chihuahua, México", Revista Forestal Baracoa, 32 (2), Instituto de Investigaciones Forestales de Cuba, La Habana, pp. 11-17 (2013).

Susana Vázquez-Álvarez. Mexicana. Maestra en ciencias en agronegocios, Universidad Autónoma de Chihuahua. Su línea de investigación actual es desarrollo forestal comunitario y aborda principalmente temas relacionados con el desarrollo de las empresas forestales comunitarias en México, Evaluación del desarrollo forestal sustentable y la planeación y evaluación del desarrollo forestal sustentable. Entre sus últimas publicaciones destacan: en coautoría: "Estrategia multidimensional para el desarrollo forestal sustentable en el ejido forestal Tetahuichi, Chihuahua, México", Revista Forestal Baracoa, 32 (2), Instituto de Investigaciones Forestales de Cuba, La Habana, pp. 11-17 (2013); Desarrollo de la Asociación Regional de Silvicultores "Baja Tarahumara", A. C., Urique, Chihuahua, Mexico. Plan de negocios y empresa social forestal, Conacyt-Conafor-Universidad Autónoma de Chihuahua, Chihuahua, 97 pp. (2014); La competitividad de las 
empresas sociales forestales en México: De la PROFORTARAH a la certificación: Las Empresas sociales forestales de Chibuahua: Los ejidos: La Trinidad y Aboreachi. Chihuahua, Universidad Autónoma de Chapingo, Chapingo, en prensa, 118 pp. (2013).

José Ciro Hernández-Díaz. Mexicano. Doctor (Ph.D.) en economía forestal, Colorado State University. Actualmente es profesor-investigador de la Universidad Juárez del Estado de Durango-Instituto de Silvicultura e Industria de la Madera, Durango. Ha sido investigador forestal y coordinador del doctorado en ciencias agropecuarias y forestales de la misma Universidad. Sus áreas de interés en investigación son: análisis económétricos y de rentabilidad de actividades forestales, abastecimiento de trocería y leñas (aprovechamiento forestal), manejo y ordenación de montes, monitoreo forestal. Entre las últimas publicaciones destacan. En coautoría: "Potencial y eficiencia de producción de semilla de Pinus engelmannii Carr., en tres rodales semilleros del estado de Durango, México", Madera y Bosques, 18 (3), Instituto de Ecología, A. C., Xalapa, pp. 7-21 (2012); "Aplicación de técnicas multicriterio en el manejo integral forestal en Durango, México", Madera y bosques, 15 (1), Instituto de Ecología A. C., Xalapa, pp. 27-46 (2009); "Potencial y eficiencia de producción de semilla de Pinus engelmannii Carr., en tres rodales semilleros del estado de Durango, México", Madera y Bosques, 18 (3), Instituto de Ecología A. C., Xalapa, pp. 7-21 (2012).

Humberto Luján-Álvarez. Doctor en administración por la Universidad Autónoma de Chihuahua. Actualmente es docente investigador perteneciente a la Dirección General de Educación Tecnológica Industrial (DGETI) dependiente de la Secretaría de Educación Pública, y profesor del programa doctoral en la Facultad de Contaduría y Administración de la Universidad Autónoma de Chihuahua. Es vocal académico de la Academia Nacional de Investigación y Desarrollo Tecnológico de la DGETr. Su línea de investigación es desarrollo forestal sustentable. Entre las últimas publicaciones destacan: "Cadena productiva forestal de la forestería comunitaria en Chihuahua, México", Revista Mexicana de Agronegocios, Agribusiness Review for Mexico and Latin America, Año XV, Número Especial, Sociedad Mexicana de Administración Agropecuaria, A. C., Torreón, pp. 82-95 (2011); "Forestería comunitaria y su cadena productiva forestal en Chihuahua", $3^{\circ}$ Congreso Internacional de Investigación CIPITECH, CIPITECH, Parral, pp. 90-97 (2010); La globalización económica y el futuro de la forestería comunitaria sustentable en México, Universidad Autónoma de Chihuahua-Conafor-Conacyt, Delicias, 58 pp. (2007). 